\title{
Suppression of tumorigenicity 2 after exercise: a systematic review
}

\author{
Ana M. Costa ${ }^{1}$, Rafael Teixeira ${ }^{2}$, Eduardo M. Vilela ${ }^{2}$, Ana Tavares ${ }^{2}$, Susana Torres ${ }^{2}$, Francisco Sampaio ${ }^{2}$, \\ Madalena Teixeira ${ }^{2}$, Ricardo Fontes-Carvalho ${ }^{2,3}$, José Pedro Nunes ${ }^{1}$ \\ ${ }^{1}$ Faculty of Medicine, University of Porto; ${ }^{2}$ Cardiology Department, Centro Hospitalar de Vila Nova de Gaia/Espinho; \\ ${ }^{3}$ Cardiovascular Research Center (UniC), Faculty of Medicine, University of Porto, Portugal
}

\begin{abstract}
Exercise is a pivotal physiological activity, associated with benefits. Whilst the importance of physical activity is consensual along different steps of the cardiovascular (CV) continuum, there has been interest in assessing the $\mathrm{CV}$ adaptations to vigorous exercise. Indeed, exercise can be associated with increases in cardiac biomarkers, though the scope of this observation remains elusive. Interleukin 1 receptor related protein, Suppression of tumorigenicity 2 (ST2) is a biomarker related to the pathophysiology of fibrosis, having shown promise in the study of heart failure. Knowledge of ST2 kinetics could improve understanding of the mechanistic pathways related to $\mathrm{CV}$ adaptations to exercise. To assess the current state-of-the-art concerning ST2 levels after exercise in healthy individuals. A systematic review was carried out on three databases (Pubmed, ISI Web of Science and Scopus), up to October 2020, using the queries "ST2" or "ST-2" + "exercise" or "running". A total of six studies were included in the review, encompassing 349 subjects (73\% male gender) in which
\end{abstract}

Correspondence: Ana M. Costa, Faculty of Medicine, University of Porto, Alameda Prof. Hernâni Monteiro, 4200-319 Porto, Portugal. Tel. +351.225.513600.

E-mail: anafmartinscosta@gmail.com

Key words: Exercise; ST2; biomarkers; sports cardiology; prevention.

Contributions: All authors equally contributed to manuscript redaction and data treatment. All the authors have read and approved the final version of the manuscript and agreed to be accountable for all aspects of the work.

Conflict of interest: The authors declare that they have no competing interests, and all authors confirm accuracy.

Ethics approval: Not applicable.

Received for publication: 9 March 2021.

Accepted for publication: 12 July 2021.

${ }^{\circ}$ Copyright: the Author(s), 2021

Licensee PAGEPress, Italy

Monaldi Archives for Chest Disease 2022; 92:1839

doi: 10.4081/monaldi.2021.1839

This article is distributed under the terms of the Creative Commons Attribution Noncommercial License (by-nc 4.0) which permits any noncommercial use, distribution, and reproduction in any medium, provided the original author(s) and source are credited.
ST2 was assessed. Most studies reported increases in ST2 levels after exercise. Three studies, encompassing a total of 219 individuals, described a cut-off level of $35 \mathrm{ng} / \mathrm{dL}$ for ST2. In these, $92.7 \%$ of subjects had ST2 levels above this cut-off after exercise (running in all studies). Most studies report increased levels of ST2 after exercise, with an important number of individuals exceeding the $35 \mathrm{ng} / \mathrm{dL}$ threshold. Given the small number of individuals represented and the lack of imaging data and long-term follow-up, further prospective larger studies should target this.

\section{Introduction}

Physical activity (PA) is one of the pillars of a healthy lifestyle [1-3]. Exercise is associated with a myriad of beneficial effects, ranging from reductions in the prevalence of several cardiovascular diseases and the incidence of different cancers, to improvements in quality of life and an overall increased longevity [3-5]. Given this background, promotion of regular moderate PA has gained a spotlight among contemporary preventive approaches $[1,6]$.

Exercise can affect several distinct systems, exerting its effects by a plethora of mechanisms ranging from improvements in the cardiovascular and respiratory systems, to musculoskeletal and metabolic adaptations [7-10]. Whilst the positive effects of regular moderate PA are currently consensual over a wide range of settings, ranging from healthy individuals to those with different pathologies [1114], the overall effects of prolonged strenuous exercise have become a source of interest [15-17]. Indeed, different reports have shown potentially deleterious cardiovascular effects of prolonged strenuous exercise, though the specific mechanisms underlying these as well as their relative impact remain to be further ascertained [16,18-21].

Biomarkers of cardiac injury and strain, such as troponins and natriuretic peptides, play a paramount role in the contemporary diagnosis and management of several cardiovascular pathologies [22-24]. Interestingly, exercise such as marathon running and triathlon can be associated with increases in the levels of different cardiac biomarkers [25-27]. Whilst this, the full scope of cardiac biomarker elevations after exercise remains elusive [25,28,29]. Given the current number of individuals undergoing intense exercise, further knowledge on the cardiovascular adaptations as well as on the mechanistic pathways associated is of importance, as to further refine this relationship [24,28].

Over the years, several novel biomarkers have been under study in the context of cardiovascular disease [22]. Among these, suppression of tumorigenicity 2 protein (ST2), a member of the interleukin (IL)-1 receptor family, which can be expressed in several cells in different settings, has been the focus of interest [3034]. This biomarker can be expressed by both cardiac and extrac- 
ardiac sites, playing a role in the pathophysiological mechanisms of myocardial fibrosis and remodelling [32,34-36]. Notably, some studies have shown the potential of ST2 in heart failure, further reinforcing its clinical importance [37-39]. Given this background, the profile of ST2 kinetics among athletes could further improve the current knowledge underlying cardiac adaptations (and potential maladaptations) in the face of exercise training [24,40,41].

This review aimed at addressing the impact of exercise in ST2 levels among healthy individuals, and to present a pragmatic appraisal of the current literature on this field. This is, to the best of our knowledge, the first systematic review on this specific topic and could thus further improve current knowledge on the kinetics of different cardiac biomarkers after exercise, a topic of considerable translational relevance.

\section{Methods}

\section{Search strategy}

The study started with a search on three databases, Medline (PubMed), ISI Web of Science and Scopus, using the queries "ST2" or "ST-2" + "exercise" or "running" (Figure 1).

The search took place between September and October 2020 , and no articles were excluded based on publication date. The aim of the search was to identify studies evaluating levels of ST2 before and after exercise. The query resulted in 105 articles on the PubMed database, 97 on ISI Web of Science and 68 on Scopus. No additional studies were found after searching the references of previous review articles.

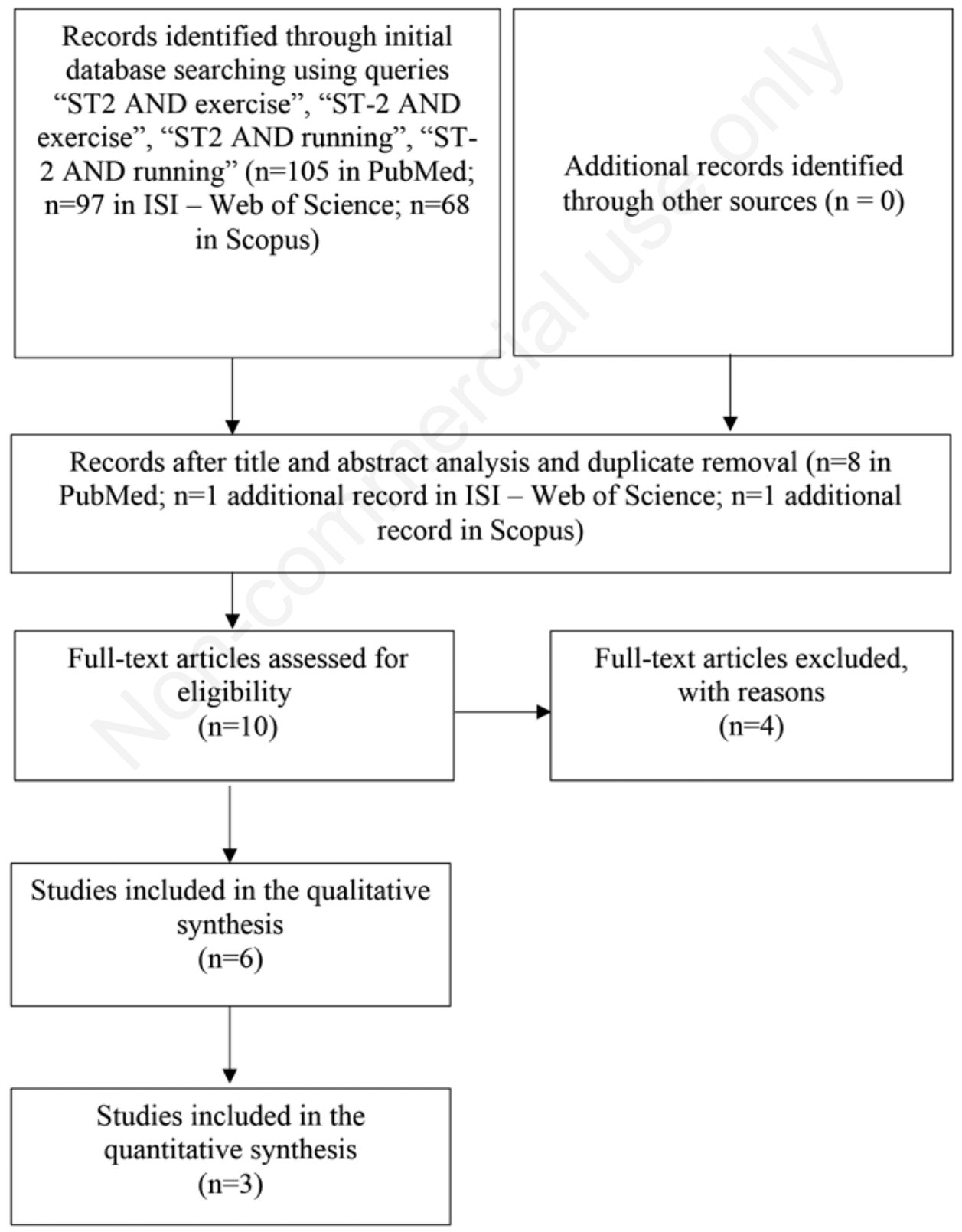

Figure 1. Flowchart showing the literature search method. 


\section{Inclusion criteria}

Only human studies were included. It was mandatory for the studies to evaluate the levels of the selected biomarker (ST2) before and after exercise (regardless of type, intensity, or duration). Though assessing levels of this biomarker after a pre-specified period of training could be of interest, the aim of this review was to assess ST2 variation after an acute bout of exercise.

To be included in the quantitative synthesis, the study had to report the cut-off used to define the upper reference limit (normal range) used.

\section{Exclusion criteria}

This review aimed at presenting data concerning healthy (or presumably healthy) subjects. As such, articles in which individuals were selected because they had a specific pathology were excluded. Additionally, case reports as well as articles written in languages other than English and studies containing less than ten subjects were also excluded.

\section{Summary measure}

The main summary measure in the quantitative synthesis was the number of individuals exceeding the reference levels (as defined in the different studies) after exercise.

The number of participants in some studies was calculated from the published value corresponding to the percentage.

\section{Quality assessment of studies and data extraction}

Study quality and eligibility were individually assessed by three investigators. Different opinions regarding the relevance of articles were solved by consensus between the authors.

\section{Results}

From title and abstract analysis, ten articles were included, and this set of articles was analyzed by the authors [24,29,42-49]. Two studies were subsequently excluded, as they lacked ST2 assessment both before and after exercise $[46,49]$. Two other studies were excluded as they did not assess ST2 levels after an acute bout of exercise, analyzing its levels after a period of training $[43,45]$. A flowchart depicting the literature search method, as well as the resulting number of articles selected, is displayed in Figure 1.

A total of six articles, published between 2016 and 2020 and encompassing a total of 349 subjects in which ST2 was assessed were included [24,29,42,44 47,48]. Table 1 presents the main characteristics of the different studies. The most common type of exercise was running, and most subjects (73\%) were male. Most studies reported on increases in ST2 levels after exercise, as reported in Table 2.

Table 3 shows the number of participants with ST2 levels above the reference level (as defined in the different studies) after exercise (up to three hours after). As shown, after exercise (running in all studies in the quantitative synthesis) $92.7 \%$ exceeded this cut-off, whereas at baseline a total of $49.8 \%$ of individuals had ST2 levels above the pre-specified threshold.

\section{Discussion}

In the present report, a systematic review was undertaken to assess the current state-of-the-art concerning ST2 kinetics after exercise, a pivotal physiologic activity, among healthy individuals. Most studies reported on increases in the levels of ST2 after exercise (running in most cases), as shown in Table 2.

Physical exercise and resistance training can be associated with changes in different cardiac biomarkers, such as troponin $[10,16,25,50]$. Since the first descriptions of exercise-induced cardiac troponin increase over thirty years ago, several underlying mechanisms have been proposed, ranging from reversible cell injury (with ensuing increased membrane permeability) to myocardial necrosis $[10,51]$. Importantly, though the high range of individuals presenting elevated cardiac troponin levels (namely when assessed by high-sensitivity assays) after intense exercise as well as the kinetics of this biomarker in this setting would argue, in most individuals, in favour of a reversible phenomenon, the specific pathophysiological mechanisms underlying this observation as well as its long-term implications are still not fully specified $[10,52,53]$.

Some studies have suggested that the accumulation of multiple acute bouts of high-intensity exercise during prolonged training could induce detrimental cardiac adaptations [25,54]. Interestingly, exercise can have a distinct hemodynamic impact in the left and right ventricles, and some studies report that athletes have a higher rate of fibrosis [21,54,55]. However, different studies reporting increases in cardiac troponin after exercise have not shown evidence of fibrosis, when assessed by cardiac magnetic resonance imaging (MRI) [56,57]. Interestingly, increases in galectin-3 (a marker of fibrosis) levels after exercise in the absence of myocardial fibrosis by cardiac MRI has also been reported, and postulated to be of extracardiac origin [58]. Given the role of fibrosis as a fundamental component of the adverse structural remodelling of the myocardium in the failing heart, these complex data have garnered interest [16]. Whilst this, as recently expertly reviewed by Malek et al., the significance of these findings remains to be further characterized [20]. Moreover, recent data derived from the UK Biobank cohort do not report on an increased risk of cardiovascular disease among healthy individuals undergoing vigorous exercise [59]. Additionally, a different study, also based on the UK Biobank cohort, did not show an increased risk of ventricular arrythmia among individuals performing vigorous PA [60]. As such, the overall effect of intense PA on the cardiovascular system remains a topic under active investigation.

ST2 is a promising and comprehensive biomarker, with an important role in several diseases [34,36,38]. ST2 has two isoforms, a transmembrane (ST2L) and a circulating (or soluble, sST2), which interact with IL-33 having protean effects, namely in terms of fibrosis and the inflammatory response [31,32,61]. sST2 can bind to IL-33 and limit the interaction between IL-33 and ST2L, thus hindering its beneficial effects $[31,39]$. Studies have illustrated the potential of sST2 levels in terms of prognostication, namely in the setting of heart failure $[33,37,61,62]$. Though sST2 levels vary in accordance with several factors (such as patient gender and extra-cardiac conditions), levels above $35 \mathrm{ng} / \mathrm{mL}$ have been associated with a worse prognosis in this context [31,36,63$65]$. Given this background, assessing the ST2 response to acute exercise could provide further insights into the cardiac (and overall cardiovascular) effects of exercise.

Most studies in this review reported increases in ST2 levels after exercise [24,29,42,44,47]. Increases in ST2 levels were related, in some studies, to exercise duration as well as type of PA $[24,29,44]$. In addition, when assessing studies which provided data on the number of individuals exceeding the cut-off of 35 $\mathrm{ng} / \mathrm{mL}$, a total of $92.7 \%$ of individuals exceeded this level $[24,29,44]$. Interestingly, while Le Goff et al. reported that ST2 
Table 1. Overview of the selected studies.

\begin{tabular}{|c|c|c|c|c|c|c|}
\hline Study (year) & n & $\begin{array}{l}\text { Male/female } \\
\text { ratio }\end{array}$ & $\begin{array}{l}\text { Mean age } \\
\text { (years) }\end{array}$ & $\begin{array}{l}\text { Type of } \\
\text { exercise }\end{array}$ & $\begin{array}{l}\text { Biomarkers } \\
\text { assessed }\end{array}$ & $\begin{array}{c}\text { Time of sample } \\
\text { collection }\end{array}$ \\
\hline Bekos et al. (2016) [42] & $34 ; 36$ & $24 / 10 ; 19 / 17$ & $36.8 ; 36.9$ & $\begin{array}{l}\text { Running different } \\
\text { lengths: marathon, } \\
\text { half-marathon }\end{array}$ & $\begin{array}{c}\text { ST2 } \\
\text { CRPCK, } \\
\text { K-MBCK18 } \\
\text { GGT } \\
\text { HMGB1 } \\
\text { IL-1RA } \\
\text { IL-33 } \\
\text { Lactate } \\
\text { Na, creatinine } \\
\text { RAGE } \\
\text { RBC, } \\
\text { WBC, } \\
\text { platelets }\end{array}$ & $\begin{array}{c}\text { Before, } \\
\text { immediately after } \\
\text { and 2-7 days } \\
\text { after the race }\end{array}$ \\
\hline Roca et al. (2017) [24] & 79 & $57 / 22$ & 39 & Running (marathon) & $\begin{array}{c}\text { ST2CK } \\
\text { hsTnT } \\
\text { NT-proBNP }\end{array}$ & $\begin{array}{l}\text { Before, after } \\
\text { (1-2 hours) } \\
\text { and } 48 \text { hours } \\
\text { after the race }\end{array}$ \\
\hline Ho et al. (2017) [47] & 41 & $17 / 24$ & 17 & $\begin{array}{l}\text { Maximal exercise test } \\
\text { treadmill) }\end{array}$ & $\begin{array}{c}\text { ST2BAPCITP } \\
\text { Gal-3 } \\
\text { hsTnI } \\
\text { Periostin } \\
\text { PICPNT-proBNP }\end{array}$ & $\begin{array}{c}\text { Baseline, just after } \\
\text { and } 4 \text { hours after } \\
\text { exercise }\end{array}$ \\
\hline Sanz-de la Garza et al. (2018) [48] & 3] 17 & $13 / 4$ & 50.0 & Maximal exercise test & $\begin{array}{c}\text { ST2 } \\
\text { hs-IL-6 } \\
\text { icycle ergometer) } \\
\text { VEGF }\end{array}$ & $\begin{array}{l}\text { Baseline and just } \\
\text { after exercise }\end{array}$ \\
\hline Aengevaeren et al. (2019) [29] & 82 & $65 / 17$ & 48 & Running (marathon) & $\begin{array}{c}\text { ST2 } \\
\text { hematocrit*, } \\
\text { Hg*hsTnI }\end{array}$ & $\begin{array}{l}\text { Before and } \\
\text { after the race }\end{array}$ \\
\hline Le Goff et al. (2020) [44] & $14 ; 19 ; 27$ & $60 / 0$ & $37.7 ; 42.0 ; 45.3$ & $\begin{array}{l}\text { Running different } \\
\text { engths: 1h (control), } \\
\text { 4h (marathon, 42.195km), } \\
\text { a 8h (ultra-marathon, 67km) }\end{array}$ & $\begin{array}{c}\text { ST2 } \\
\text { CK-MB } \\
\text { hs-CRP } \\
\text { Gal-3 } \\
\text { hematocrit, Hg } \\
\text { hsTnT } \\
\text { NT-proBNP }\end{array}$ & $\begin{array}{l}\text { Before, just } \\
\text { after and } 3 \text { hours } \\
\text { after the race }\end{array}$ \\
\hline
\end{tabular}

BAP,bone alkaline phosphatase; CITP,C-terminal telopeptide of type I collagen; CRP,C-reactive protein; hs-CRP,high-sensitivity C-reactive protein; CK,creatine kinase; CK18,cytokeratin 18; CK-MB,creatine kinase isoform MB; HMGB1, high mobility group box 1; Hg hemoglobin; Gal-3 galectin-3; GGT gama-gl utamil transferase; IL-1RA,interleukin-1 receptor antagonist; hs-LL6, high-sensitivity interleukin-6; IL-33, interleukin-33; n,number of individuals; Na,sodium; NT-proBNP,N-terminal pro-hormone of brain natriuretic peptide; PICP,C-terminal propeptide of procollagen type I; RAGE,receptor of advanced glycation endproducts; RBC,red blood cells; ST2,suppression of tumorigenicity 2 protein; hsTnI,high-sensitivity troponin I; hSTnT,high-sensitivity troponin T; VEGF,vascular endothelial growth factor; WBC, white blood cells; * ${ }^{2}$ determined in a subset of individuals.

Table 2. Major findings concerning ST2, in the six articles included in the systematic review.

\begin{tabular}{|c|c|}
\hline Study (year) & Major findings \\
\hline Bekos et al. (2016) [42] & ST2 increased significantly after a marathon, returning to baseline levels after 2 to 7 days of recovery \\
\hline Roca et al. (2017) [24] & $\begin{array}{l}\text { ST2 levels above the cut-off ( } 35 \mathrm{ng} / \mathrm{dL}) \text { in } 48.7 \% \text { of individuals at baseline. } \\
\text { ST2 increased significantly immediately after a marathon, returning to baseline levels } 48 \text { hours post-race. } \\
\text { ST2 elevations directly related to race time }\end{array}$ \\
\hline Ho et al. (2017) [47] & ST2 levels increased 4 hours after exercise \\
\hline Sanz-de la Garza et al. (2018) [48] & No difference in ST2 levels after exercise \\
\hline Aengevaeren et al. (2019) [29] & $\begin{array}{l}\text { ST2 levels above the cut-off ( } 35 \mathrm{ng} / \mathrm{dL}) \text { in } 48 \% \text { of individuals at baseline } \\
\text { ST2 levels were higher in faster runners }\end{array}$ \\
\hline Le Goff et al. (2019) [44] & $\begin{array}{l}\text { ST2 levels above the cut-off ( } 35 \mathrm{ng} / \mathrm{dL} \text { ) at baseline in } 71.4 \% \text { of controls, } 63.2 \% \text { of marathon runners and } 40.7 \% \\
\text { of ultra-marathon runners } \\
\text { ST2 levels increased significantly immediately after running and continued to increase at the three-hour mark }\end{array}$ \\
\hline
\end{tabular}


levels continued to increase three hours after exercise, two studies which assessed levels further after exercise showed that these returned to baseline 48 hours and 48 hours to seven days after (respectively) $[24,42,44]$. On the other hand, some studies highlighted that an important number of subjects already displayed ST2 levels above the $35 \mathrm{ng} / \mathrm{ml}$ cut-off at baseline [24,29,44]. Notably, though myocardial production should be acknowledged, extramyocardial origin (namely in pulmonary tissue) should be considered, as increased hemodynamic load in response to chronic training could induce ST2 elevations in athletes [24,29,32,35]. In this background, the fact that in one of the studies included in the quantitative synthesis ST2 and troponin levels (which exceed cut-off values in $69 \%$ of athletes after exercise) were not correlated at any time point should also be pondered with [29]. Furthermore, the effects of exercise in terms of the overall inflammatory response should also be kept in mind, as these could be of potential importance when assessing the variation in ST2 levels $[8,29]$.

The current data, although available for only a relatively limited number of individuals, concurs as to the impact of exercise in ST2 levels, with increases after PA. This could reflect the hemodynamic stress associated with exercise (particularly in the case of intense exercise) $[29,41,66]$. Also, the notion that among this population baseline levels could exceed current cut-offs should also be mentioned, as exercise history could thus be important when interpreting these results [29]. Interestingly, and as mentioned above, prior data suggests ST2 increases in relation to diastolic load, and with a predominantly extra-myocardial origin [24,29,35]. As such, the mechanisms underlying the modulators of both baseline and post-exercise ST2 levels among athletes, as well as the biological significance of these adaptations (in terms of both the cardiovascular system as well as the possible modulation of inflammatory pathways) and their potential clinical relevance, should be the focus of further larger long-term studies.

\section{Study limitations}

There are several limitations which should be acknowledged when interpreting the present data. Firstly, the heterogeneous nature of the current data (in terms of different study designs, namely encompassing the population under study, type of exercise and timing of samples) as well as the potential for confounding factors (such as pathological issues, particularly underlying cardiovascular disease) should be considered. Secondly, follow-up (as well as sampling timing) after exercise differed. As detailed in the Discussion, whereas ST2 levels continued to increase three hours after exercise in one study, these had returned to baseline in two others which assessed levels further after exercise [24,42,44]. Given reports on the dynamic changes in ST2 concentrations

Table 3. Number of participants with ST2 levels above the reference level (as defined in the different studies) after exercise (up to three hours).

\begin{tabular}{ll}
\hline Roca et al. (2017) [24] & $69 / 79$ \\
Aengevaeren et al. (2019) [29] & $75 / 80$ \\
\hline Le Goff et al. (2020) [44] & $13 / 14$ (control) \\
& $19 / 19$ (marathon) \\
& $27 / 27$ (ultra-marathon) \\
Total & $203 / 219(92.7 \%)$ \\
\hline
\end{tabular}

among acute heart failure patients under treatment, showing rapid decreases, as well as the concept that chronic volume and pressure overload could markedly impact its levels, it would be of interest to have more data on ST2 kinetics after acute bouts of exercise, as to be able to address its major determinants [34,67,68]. Interestingly, Billebeau et al. reported that heart failure patients who underwent a cardiac rehabilitation program had significant decreases in ST2 levels (when assessed 4-6 months after), these being more pronounced according to changes in peak oxygen consumption. As such, the overall effect of chronic exercise in ST2 levels, across different populations, remains to be further ascertained [69]. Thirdly, as highlighted in the Discussion, only a relatively small number of individuals were represented, and most of these were male. Given potential differences in ST2 physiology and in the response to exercise training in terms of gender, this point should be pondered with $[31,61,70]$. Furthermore, data pertaining to imaging analysis (by means of cardiac MRI) were also not present. Finally, studies included were of short duration, and as such the long-term significance of ST2 level variation in this setting should be the focus of further studies.

\section{Conclusions}

Most studies assessing ST2 levels after exercise training among healthy individuals showed increases in this biomarker. Though data were available for only a relatively small number of individuals, $92.7 \%$ had ST2 levels above the cut-off of $35 \mathrm{ng} / \mathrm{ml}$ after exercise, pointing to a rather generalized phenomenon. Baseline levels of ST2 were also above this threshold in some individuals. No studies presented cardiac magnetic resonance imaging data or assessed clinical outcomes.

Further studies are needed to assess the clinical significance, if any, as well as the long-term prognosis associated with ST2 kinetics in the setting of intense exercise. Imaging studies could play an important role in unravelling the mechanisms underlying exerciseinduced ST2 level changes.

\section{References}

1. Piepoli MF, Hoes AW, Agewall S, et al. 2016 European Guidelines on cardiovascular disease prevention in clinical practice: The Sixth Joint Task Force of the European Society of Cardiology and Other Societies on Cardiovascular Disease Prevention in Clinical Practice. Eur Heart J 2016;37:2315-81.

2. Ross R, Blair SN, Arena R, et al. Importance of assessing cardiorespiratory fitness in clinical practice: A Case for fitness as a clinical vital sign: A scientific statement from the American Heart Association. Circulation 2016;134:653-99.

3. Sharma S, Merghani A, Mont L. Exercise and the heart: the good, the bad, and the ugly. Eur Heart J 2015;36:1445-53.

4. Patel AV, Friedenreich CM, Moore SC, et al. American College of Sports Medicine roundtable report on physical activity, sedentary behavior, and cancer prevention and control. Med Sci Sports Exerc 2019;51:2391-402.

5. Warburton DE, Nicol CW, Bredin SS. Health benefits of physical activity: the evidence. CMAJ 2006;174:801-9.

6. Virani SS, Alonso A, Benjamin EJ, et al. Heart disease and stroke statistics-2020 Update: A report From the American Heart Association. Circulation 2020;141:139-596. 
7. Fontes-Carvalho R, Azevedo AI, Sampaio F, et al. The effect of exercise training on diastolic and systolic function after acute myocardial infarction: A randomized study. Medicine (Baltimore) 2015;94:1450-6.

8. Gevaert AB, Adams V, Bahls M, et al. Towards a personalised approach in exercise-based cardiovascular rehabilitation: How can translational research help? A 'call to action' from the Section on Secondary Prevention and Cardiac Rehabilitation of the European Association of Preventive Cardiology. Eur J Prev Cardiol 2020;27:1369-85.

9. Nieman DC, Wentz LM. The compelling link between physical activity and the body's defense system. J Sport Health Sci 2019;8:201-17.

10. Vilela EM, Bastos JCC, Rodrigues RP, et al. High-sensitivity troponin after running - a systematic review. Neth J Med 2014;72:5-9.

11. Campbell KL, Winters-Stone KM, Wiskemann J, et al. Exercise guidelines for cancer survivors: Consensus statement from international multidisciplinary roundtable. Med Sci Sports Exerc 2019;51:2375-90.

12. Pelliccia A, Sharma S, Gati S, et al. 2020 ESC Guidelines on sports cardiology and exercise in patients with cardiovascular disease. Eur Heart J 2021;42:17-96.

13. Vilela EM, Ladeiras Lopes R, Torres S, et al. Differential Impact of a cardiac rehabilitation program on functional parameters in elderly versus non-elderly myocardial infarction survivors. Cardiology 2020;145:98-105.

14. Vilela EM, Ladeiras-Lopes R, Ruivo C, et al. Different outcomes of a cardiac rehabilitation programme in functional parameters among myocardial infarction survivors according to ejection fraction. Neth Heart J 2019;27:347-53.

15. Aengevaeren VL, Mosterd A, Sharma S, et al. Exercise and coronary atherosclerosis: Observations, explanations, relevance, and clinical management. Circulation 2020;141:1338-50.

16. Franklin BA, Thompson PD, Al-Zaiti SS, et al. Exercise-related acute cardiovascular events and potential deleterious adaptations following long-term exercise training: Placing the risks into perspective-an update: A Scientific statement from the American Heart Association. Circulation 2020;141:705-36.

17. O'Keefe JH, Lavie CJ. Run for your life...at a comfortable speed and not too far. Heart Month 2013;99:516-9.

18. Biscaglia S, Campo G, Sorbets E, et al. Relationship between physical activity and long-term outcomes in patients with stable coronary artery disease. Eur J Prev Cardiol 2020;27:426-36.

19. Lechner K, Spanier B, Lechner B, et al. Your athlete-patient has a high coronary artery calcification score-'Heart of Stone'. What should you advise? Is exercise safe? Br J Sports Med 2020;bjsports-2019-100769. Online ahead of print.

20. Malek LA, Bucciarelli-Ducci C. Myocardial fibrosis in athletes - Current perspective. Clin Cardiol 2020;43:882-8.

21. van de Schoor FR, Aengevaeren VL, Hopman MT, et al. Myocardial fibrosis in athletes. Mayo Clin Proc 2016;91: 1617-31.

22. Dhingra R, Vasan RS. Biomarkers in cardiovascular disease: Statistical assessment and section on key novel heart failure biomarkers. Trends Cardiovasc Med 2017;27:123-33.

23. Thygesen K, Alpert JS, Jaffe AS, et al. Fourth universal definition of myocardial infarction (2018). J Am Coll Cardiol 2018;72:2231-64.

24. Roca E, Nescolarde L, Lupon J, et al. The dynamics of cardiovascular biomarkers in non-elite marathon runners. J Cardiovasc Transl Res 2017;10:206-8.

25. Eijsvogels TM, Fernandez AB, Thompson PD. Are There dele- terious cardiac effects of acute and chronic endurance exercise? Physiol Rev 2016;96:99-125.

26. Tulloh L, Robinson D, Patel A, et al. Raised troponin T and echocardiographic abnormalities after prolonged strenuous exercise--the Australian Ironman Triathlon. Br J Sports Med 2006; 40:605-9.

27. Vilela EM, Bettencourt-Silva R, Nunes JP, et al. BNP and NTproBNP elevation after running--a systematic review. Acta Cardiol 2015;70:501-9.

28. Knechtle B, Nikolaidis PT. Physiology and pathophysiology in ultra-marathon running. Front Physiol 2018;9:1-33.

29. Aengevaeren VL, RRJ VAN Kimmenade, Hopman MTE, et al. Exercise-induced changes in soluble ST2 concentrations in marathon runners. Med Sci Sports Exerc 2019;51:405-10.

30. Griesenauer B, Paczesny S. The ST2/IL-33 axis in immune cells during inflammatory diseases. Front Immunol 2017;8:475.

31. Nah EH, Cho S, Kim S, et al. Reference interval and the role of soluble suppression of tumorigenicity 2 (SST2) in subclinical cardiac dysfunction at health checkups. J Clin Lab Anal 2020;34:e23461.

32. Pascual-Figal DA, Januzzi JL. The biology of ST2: the international ST2 consensus panel. Am J Cardiol 2015;115:3B-7B.

33. van Vark LC, Lesman-Leegte I, Baart SJ, et al. Prognostic value of serial ST2 measurements in patients with acute heart failure. J Am Coll Cardiol 2017;70:2378-88.

34. Homsak E, Gruson D. Soluble ST2: A complex and diverse role in several diseases. Clin Chim Acta 2020;507:75-87.

35. Bartunek J, Delrue L, Van Durme F, et al. Nonmyocardial production of ST2 protein in human hypertrophy and failure is related to diastolic load. J Am Coll Cardiol 2008;52:2166-74.

36. Suthahar N, Meems LMG, Ho JE, et al. Sex-related differences in contemporary biomarkers for heart failure: a review. Eur J Heart Fail 2020;22:775-88.

37. Aimo A, Januzzi JL, Jr., Bayes-Genis A, et al. Clinical and prognostic significance of sST2 in heart failure: JACC review topic of the week. J Am Coll Cardio. 2019;74:2193-203.

38. Aimo A, Vergaro G, Passino C, et al. Prognostic value of soluble suppression of tumorigenicity-2 in chronic heart failure: A meta-analysis. JACC Heart Fail 2017;5:280-6.

39. Bayes-Genis A, de Antonio M, Vila J, et al. Head-to-head comparison of 2 myocardial fibrosis biomarkers for long-term heart failure risk stratification: ST2 versus galectin-3. J Am Coll Cardiol 2014;63:158-66.

40. Pearson MJ, King N, Smart NA. Effect of exercise therapy on established and emerging circulating biomarkers in patients with heart failure: a systematic review and meta-analysis. Open Heart 2018;5:e000819.

41. Le Goff C, Farre Segura J, Dufour P, et al. Intense sport practices and cardiac biomarkers. Clin Biochem 2020;79:1-8.

42. Bekos C, Zimmermann M, Unger L, et al. Non-professional marathon running: RAGE axis and ST2 family changes in relation to open-window effect, inflammation and renal function. Sci Rep 2016;6:32315.

43. Galliera E, Lombardi G, Marazzi MG, et al. Acute exercise in elite rugby players increases the circulating level of the cardiovascular biomarker GDF-15. Scand J Clin Lab Invest 2014;74:492-9.

44. Le Goff C, Kaux JF, Farre Segura J, et al. Evolution of the slopes of ST2 and galectin-3 during marathon and ultratrail running compared to a control group. Clin Chem Lab Med 2020;58:314-21.

45. Sponder M, Lichtenauer M, Wernly B, et al. Serum heart- 
type fatty acid-binding protein decreases and soluble isoform of suppression of tumorigenicity 2 increases significantly by long-term physical activity. J Investig Med 2019;67:833-40.

46. Agoston-Coldea L, Lupu S, Hicea S, et al. Serum levels of the soluble IL-1 receptor family member ST2 and right ventricular dysfunction. Biomarkers Medicine 2014;8:95-106.

47. Ho JE, Shi L, Day SM, et al. Biomarkers of cardiovascular stress and fibrosis in preclinical hypertrophic cardiomyopathy. Open Heart 2017;4:615-23.

48. Sanz-de la Garza M, Iannino N, Finnerty V, et al. Cardiopulmonary, biomarkers, and vascular responses to acute hypoxia following cardiac transplantation. Clin Transplant 2018;32:e13352.

49. Zheng YG, Yang T, He JG, et al. Plasma soluble ST2 levels correlate with disease severity and predict clinical worsening in patients with pulmonary arterial hypertension. Clin Cardio. 2014;37:365-70.

50. Shave R, Baggish A, George K, et al. Exercise-induced cardiac troponin elevation: evidence, mechanisms, and implications. J Am Coll Cardiol 2010;56:169-76.

51. Airaksinen KEJ. Cardiac troponin release after endurance exercise: Still much to learn. J Am Heart Assoc 2020;9:1-3.

52. Aengevaeren VL, Hopman MTE, Thompson PD, et al. Exercise-induced cardiac troponin I increase and incident mortality and cardiovascular events. Circulation 2019;140:804-14.

53. Gresslien T, Agewall S. Troponin and exercise. Int J Cardiol 2016;221:609-21.

54. La Gerche A, Burns AT, Mooney DJ, et al. Exercise-induced right ventricular dysfunction and structural remodelling in endurance athletes. Eur Heart J 2012;33:998-1006.

55. Breuckmann F, Mohlenkamp S, Nassenstein K, et al. Myocardial late gadolinium enhancement: Prevalence, pattern, and prognostic relevance in marathon runners. Radiology 2009;251:50-7.

56. Hanssen H, Keithahn A, Hertel G, et al. Magnetic resonance imaging of myocardial injury and ventricular torsion after marathon running. Clin Sci (Lond) 2011;120:143-52.

57. Trivax JE, Franklin BA, Goldstein JA, et al. Acute cardiac effects of marathon running. J Appl Physiol (1985) 2010;108:1148-53.

58. Hattasch R, Spethmann S, de Boer RA, et al. Galectin-3 increase in endurance athletes. Eur $\mathrm{J}$ Prev Cardiol 2014;21:1192-9.

59. Ramakrishnan R, Doherty A, Smith-Byrne K, et al. Accelerometer measured physical activity and the incidence of cardiovascular disease: Evidence from the UK Biobank cohort study. PLoS Med 2021;18:e1003487.

60. Elliott AD, Linz D, Mishima R, et al. Association between physical activity and risk of incident arrhythmias in 402406 individuals: evidence from the UK Biobank cohort. Eur Heart J 2020;41:1479-86.

61. Sharim J, Daniels LB. Soluble ST2 and soluble markers of fibrosis: Emerging roles for prognosis and guiding therapy. Curr Cardiol Rep 2020;22:41.

62. Wu AH, Wians F, Jaffe A. Biological variation of galectin-3 and soluble ST2 for chronic heart failure: implication on interpretation of test results. Am Heart J 2013;165:995-9.

63. Mueller T, Dieplinger B. Soluble ST2 and galectin-3: what we knowand don't know analytically. eJIFCC 2016;3:224-37.

64. Nishimura M, Brann A, Chang KW, et al. The confounding effects of non-cardiac pathologies on the interpretation of cardiac biomarkers. Curr Heart Fail Rep 2018;15:239-49.

65. Watson CJ, Tea I, O'Connell E, et al. Comparison of longitudinal change in $\mathrm{SST} 2$ vs BNP to predict major adverse cardiovascular events in asymptomatic patients in the community. J Cell Mol Med 2020;24:6495-9.

66. Mirna M, Lichtenauer M, Wernly B, et al. Novel cardiovascular biomarkers in patients with cardiovascular diseases undergoing intensive physical exercise. Panminerva Med 2020;62:135-42.

67. Magini A, Farina S, Riggio D, et al. ST2 and B-type natriuretic peptide kinetics during exercise in severe heart failure. Eur J Heart Fail 2018;20:1494-5.

68. Maisel AS, Richards AM, Pascual-Figal D, et al. Serial ST2 testing in hospitalized patients with acute heart failure. Am J Cardiol 2015;115:32B-7.

69. Billebeau G, Vodovar N, Sadoune M, et al. Effects of a cardiac rehabilitation programme on plasma cardiac biomarkers in patients with chronic heart failure. Eur J Prev Cardiol 2017;241127-35.

70. Witvrouwen I, Van Craenenbroeck EM, Abreu A, et al. Exercise training in women with cardiovascular disease: Differential response and barriers - review and perspective. Eur J Prev Cardiol 2021;28:779-90. 